$\mathbb{T}$ periodica polytechnica

Civil Engineering

$54 / 2(2010) 107+116$

doi: 10.3311/pp.ci.2010-2.06

web: http://www.pp.bme.hu/ci

(c) Periodica Polytechnica 2010

RESEARCH ARTICLE

\section{Experimental study of the}

overconsolidation and saturation

effects on the mechanical

characteristics and residual strength of

Chlef river sandy soil

\author{
Noureddine Della / Hanifi Missoum / Ahmed Arab / Mostefa Belkhatir
}

Received 2010-03-29, revised 2010-07-21, accepted 2010-07-30

\begin{abstract}
This paper presents a laboratory study of the influence of the saturation evaluated in terms of Skempton's pore pressure coefficient $(B)$ and overconsolidation ratio $(O C R)$ on the behavior of Chlef sand. The study is based on drained and undrained triaxial compression tests which were carried out for Skempton's pore pressure coefficient varying between 13 and $90 \%$ and OCR varying between 1 and 8. Tests were conducted on medium dense sand samples having an initial relative density Index Id = 0.5 at an effective stress of $100 \mathrm{kPa}$. The paper is composed of two parts. The first one presents the characteristics of the sand used in this study, the second provides an analysis of the experimental results and discusses the influence of Skempton's pore pressure coefficient $(B)$ and OCR on the mechanical characteristics of the sand. The tests show that the increase in the Skempton's pore pressure coefficient $(B)$ reduces the soil dilatancy and amplifies the phase of contractancy and reduces the frictional and characteristic angle of the sand. The increase of OCR improves the stiffness of sand and accelerates the appearance of dilatancy; and increases frictional and characteristic angle of the sand. Moreover, the present study focuses on the effect of saturation and overconsolidation on the residual shear strength of sand.
\end{abstract}

\section{Keywords}

sand $\cdot$ monotonic $\cdot$ drained $\cdot$ undrained $\cdot$ saturation $\cdot$ overconsolidation

\section{Noureddine Della}

Laboratory of materials sciences and environment, University of Chlef, Route de sendjas BP 151 Chlef 02000, Algeria

e-mail: nour_della@yahoo.fr

\section{Hanifi Missoum}

Department of Civil Engineering, University of Mostaganem, Site 1, route de Belahcel BP 300,Mostaganem 27000, Algeria

e-mail: hanifimissoum@yahoo.fr

\section{Ahmed Arab}

Mostefa Belkhatir

Laboratory of materials sciences and environment, University of Chlef, Route de sendjas BP 151 Chlef 02000, Algeria

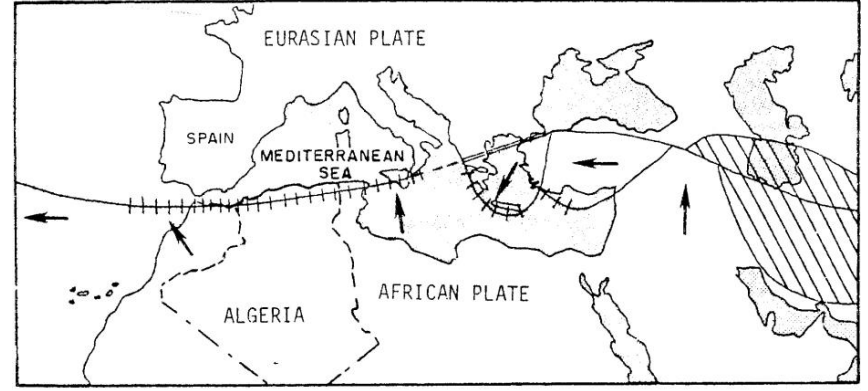

Fig. 1. Movement of Europe-Afrique plate

\section{Introduction}

The region of Chlef (formerly known as El-Asnam) situated to the North of Algeria about $200 \mathrm{~km}$ to the west of the capital Algiers, by its proximity of the contact of the continental European and African plates as it is shown by Fig. 1] is constantly a very instable zone subjected to an intense seismic activity. During the last centuries, it underwent destructive earthquakes in 1922, 1934, and 1954. This last earthquake of magnitude 6.7 which have been described well enough by Rothé (1955) [28], Thevenin (1955) [32] and Mckenzie (1972) [21], had caused the death to 1340 people and important damages on the different civil engineering structures as well as the appearance of the soils sliding and liquefaction phenomenon.

October $10^{\text {th }}, 1980$ at $13 \mathrm{~h} 25$ (local time), the region was the theater of a strong earthquake of a magnitude of 7.3 according to the calculations of Papastamatiou [25], followed by two important jolts of magnitudes 6 and 6.1 to some hours of interval and numerous retorts appeared during several months [24]. The main Shock generated an important inverse fault of about $40 \mathrm{~km}$ long appeared in surface [2]. The epicenter of this earthquake was localized in the North East of El-Asnam around the village of Beni Rached.

The disaster of October 10, 1980 provoked numerous losses in human lives (about 3000 deaths) the destructions of buildings in high number and the important damages to the linking infrastructures and to public equipment. If we put aside the merely tectonic demonstrations, as the spectacular fault appeared near 


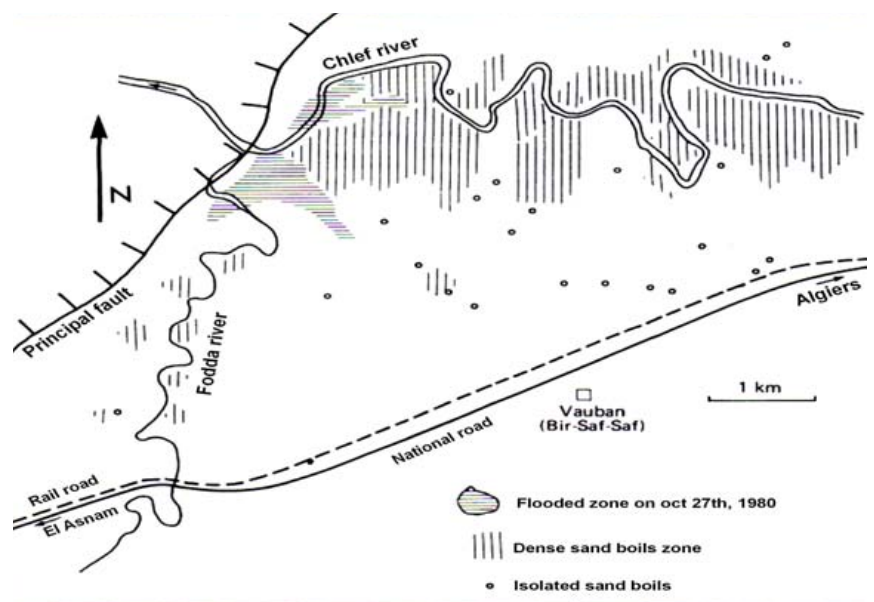

Fig. 2. Valley of the Chlef river and localization of the sand boils due to the liquefaction phenomenon

El-Asnam. The seismic vibration also generated a certain number of geodynamic phenomena to the surface of the soil: movements of ground of varied nature and size, and especially the liquefaction of the sandy soils following a loss of resistance to the shearing.

According to Durville and Méneroud (1982) the phenomenon of liquefaction appeared on a vast alluvial valley crossed by the Chlef river and to the zone of confluence of this river with the Fodda river as is shown in Fig. 2

\section{Literature review}

The risk of liquefaction occupies an important place in the design of urban planning construction. Liquefaction occurs due to an increase in the excess pore water pressure and a corresponding decrease in the effective overburden stress in a soil deposit. The soil looses its strength and behaves like a liquid.

The experimental study of the behavior of the soils requires good skills of the parameters that influence on the liquefaction resistance. Among these parameters, we can enumerate the overconsolidation and saturation of the samples in the laboratory which was the topic of several former researches.

In the neighbourhoods of the town of Chlef, unsaturated zones exist on the top of the phreatic ground which underwent a significant folding back following the dryness which touches the area since the Eighties. During the past decades, advanced researches helped us better understand the liquefaction of the grounds based on experiments carried out in laboratory, the physical modeling and the numerical analysis. The majority of the investigations on the liquefaction of the granular soils were based on completely saturated material. The study of the influence of the saturation degree on the liquefaction of the soils is of practical interest, because we often find structures built on the top of the phreatic ground; what implies the presence of partially saturated grounds. The incidence of a partial saturation on cyclic resistance was approached in a theoretical way by [19]. Mulilis et al. [22] investigated the effect of the saturation de- gree on the liquefaction of Monterrey sand. They noted that the variation of the Skempton's coefficient B between 0.91 and 0.97 does not significantly affect the liquefaction of this sand. This influence depends on the type of soil, the density and the initial confining pressure. However, the recent results of the in-situ tests include the measurements of the velocity of the compression waves $(\mathrm{Vp})$, and indicate that the condition of partial saturation can exist above the level of the phreatic ground for a few meters due to the presence of bubbles of air [13] and [23] or the presence of gas bubbles in the marine sediments and sands containing oils as noted by Mathiroban and Grozic (2004) [20].The effects of a condition of partial saturation on liquefaction were approached by some researchers [3, 20, 26, 34] .The condition of saturation of soil samples in laboratory can be evaluated by measuring the value of the coefficient of Skempton B or the speed of compression waves Vp as suggested by Ishihara et al. (2001) [13] The results of the laboratory tests showed that the resistance to the liquefaction of sands increases when the saturation degree decreases [6, 7, 13, 14, 19, 33, 34, 36].

Mullilis et al. (1978) [22] and Tatsuoka et al. (1986) [31] showed that in the case of loose sands, a good saturation requires high values of the coefficient B. On the other hand, for stiffer materials, the problem seems less critical. Sheriff et al. (1977) show that a fine or clayey sand can be considered saturated if the value of B exceeds 0.8, Chaney (1978) precised that the coefficient B must exceed 0.96 so that the soil is well saturated. On the other hand, Giroud and Cordary (1976) noted that for values of B superiors to 0.85 , the degree of saturation is very close to 1 . Tests of liquefaction were carried out by Yoshimi et al. (1989) [36] on the sand of Toyoura of medium density ( $I d=0.60)$ with samples having various degrees of saturation. The results show that the degree of saturation significantly affects the resistance to liquefaction: With a coefficient $B$ higher than 0.8 , it is enough to apply three cycles to have a liquefaction of the sample; whereas we need eight cycles to obtain liquefaction of the specimens having a coefficient B close to 0.5.

For the study of the microzonation and the urban expansion of the town of Chlef after the earthquake of October 1980, and due to the demographic explosion that the country knew; several sites were selected to shelter new constructions. These sites required adjustments and scourings of very significant volumes of ground; after removal of these ground masses, these grounds are overconsolidated. The preconsolidated soils (preloaded) are often found in nature, especially with the melting of ice, scouring of the grounds, phenomenon of erosion, fluctuation of the phreatic underground etc. Several researchers showed that the overconsolidation has a significant effect on resistance to liquefaction of the soils (Ishihara and Takutsu, 1979 [12], Seed et al., 1975 [29]; Seed and Peacock, 1971 [30]). The results obtained by Ishihara et al. (1978) [11] show on soils having various contents of fine elements that the resistance to liquefaction increases with the overconsolidation. This effect is accentuated with the increase in the percentage of fine elements. By carrying 


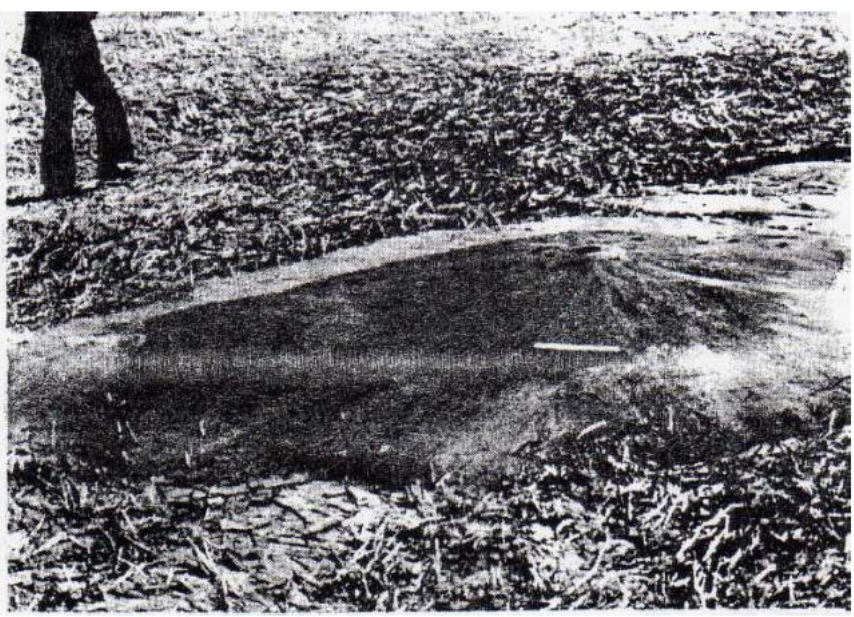

Fig. 3. Sand boils due to the liquefaction phenomenon at Chlef region

out cyclic tests on the Hostun sand, Bouferra (2000) [6], found that with a coefficient of overconsolidation of 7 , liquefaction is obtained at the end of 17 cycles; whereas with a normally consolidated sample, 6 cycles are needed to obtain liquefaction.

In this paper, the results of a laboratory study of the influence of the degree of saturation and of the overconsolidation ratio (OCR) on the behavior of granular sand, are presented. These tests make it possible to better understand the influence of saturation and the overconsoliation on the mechanical behavior of granular sand. The article is composed of two parts. In the first part, we present the material used; the second part gives an analysis of the experimental results of the tests carried out and discusses the influence of the degree of saturation and the OCR on the mechanical characteristics of the sand of Chlef.

\section{Material tested and experimental procedures}

The tests were carried out on the sand of Chlef containing $0.5 \%$ of silt of the Chlef River. The granular grading curve of sand used is given in Fig. 4. The sand of Chlef is a medium sand, rounded with an average diameter $D 50=0.45 \mathrm{~mm}$. The silt contained is not very plastic with an index of plasticity of $6 \%$. Table 1 gives the physical characteristics of the sand used. The tests have been carried out on specimens collected from the region where the phenomenon of liquefaction was observed during the last earthquake near the Chlef River (see Fig. 3) with an index of density $I d=0.50$ and at initial confining pressure of $\sigma_{c}{ }^{\prime}=100 \mathrm{kPa}$.

The used experimental device is presented in Fig. 5. It contains:

- An autonomous triaxial cell type Bishop and Wesley (Bishop and Wesley, 1975),

- two controllers of pressure/volume type GDS (200 cc),

- a void pump joined to a reservoir in order to deaire the demineralized water,

- a microcomputer equipped with software.

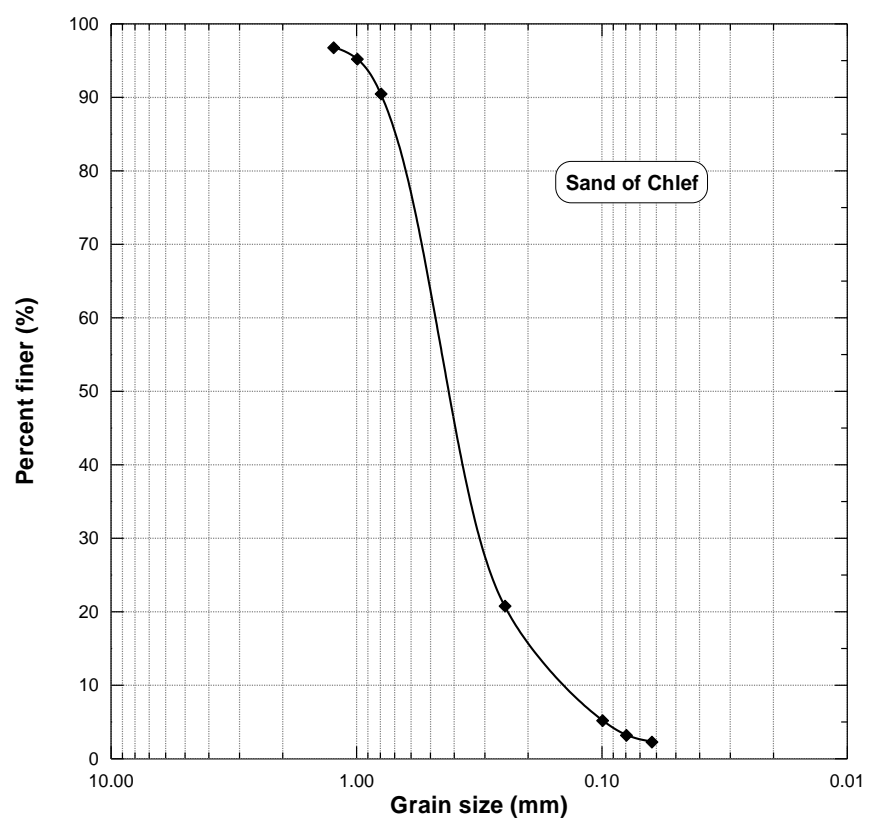

Fig. 4. Grain size distribution of tested material

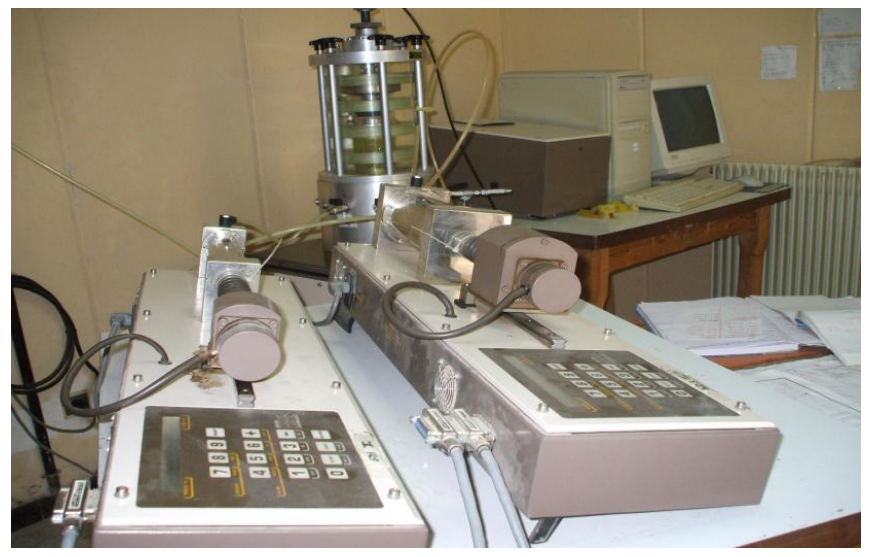

Fig. 5. The experimental device used

Tab. 1. Physical characteristics of Chlef sand

\begin{tabular}{cc}
\hline Material & O/Chlef \\
\hline$e_{\min }$ & 0.54 \\
\hline$e_{\max }$ & 0.99 \\
\hline$\gamma_{\text {dmin }}\left(\mathrm{g} / \mathrm{cm}^{3}\right)$ & 1.34 \\
\hline$\gamma_{d \max }\left(\mathrm{g} / \mathrm{cm}^{3}\right)$ & 1.73 \\
\hline$\gamma_{s}\left(\mathrm{~g} / \mathrm{cm}^{3}\right)$ & 2.67 \\
\hline$C u\left(D_{60} / D_{10}\right)$ & 3.2 \\
\hline$D_{50}(\mathrm{~mm})$ & 0.45 \\
\hline$D_{10}(\mathrm{~mm})$ & 0.15 \\
\hline Grains shape & Rounded \\
\hline
\end{tabular}

\subsection{Sample preparation}

The sample preparation method used is dry pluviation where the dry soil is deposited in the mould using a funnel with a rigorous control of the drop height of the sand which must be quasi- 


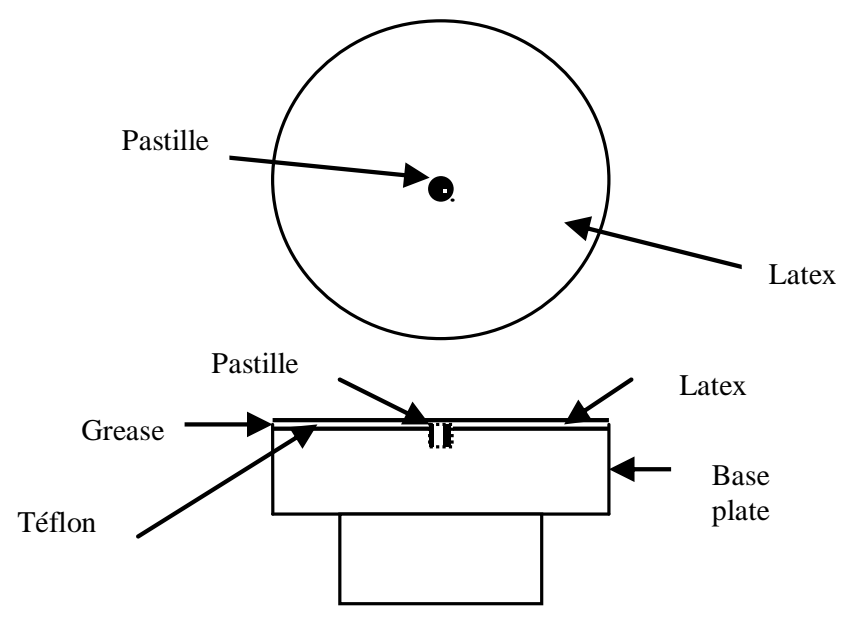

Fig. 6. Antifrettage system

null for the loose samples. With the aim of having medium dense homogeneous samples, we have used the method recommended by Ladd (1978) [16]; this method consists in dividing the sample in several layers. The relative density of each layer varies to $1 \%$ from bottom upwards. The average layer has the same value of the relative density as the sample.

The used samples are cylindrical in shape of $70 \mathrm{~mm}$ of diameter and $70 \mathrm{~mm}$ height $(l / d=1)$. To make sure of a good homogeneity of the stresses and deformations within the samples, several researchers (Lee, 1978 [18]; Robinet et al., 1983 [27]; Tatsuoka et al., 1984 [31]; Colliat 1986 [8]; Al Mahmoud 1997 [1]) insisted on the need for reducing frictions between the sample and the superior and inferior base plates; this can be obtained by base plates of smooth or lubricated surface (antifrettage system).The antifrettage system used is represented in Fig. 6 (Al Mahmoud, 1997 [1]). The sand mass to be set up is evaluated according to the desired density (the initial volume of the sample is known), the state of density of the sample being defined by the relative density:

$$
I_{D}=\frac{\left(e_{\max }-e\right)}{\left(e_{\max }-e_{\min }\right)}
$$

\subsection{Saturation of the sample}

To obtain a good degree of saturation, the technique of carbon dioxide worked out by Lade and Duncan (1973) [15] was used. The sample is firstly swept by carbon dioxide during twenty minutes, then we let the deaerated and demineralized water circulate until collecting a volume of water superior to one and a half the volume of the sample. To be able to obtain samples with various degrees of saturation, we have varied the time of passage of carbon dioxide and the duration of duct drainage deaerated water through the sample.

\subsection{Consolidation of the sample}

In order to consolidate the sample, a rise in pressure in the cell $\left(\sigma_{3}\right)$ and inside the sample a backpressure (U) were parallelly applied. The application of backpressure improves the quality of saturation by compressing the microbubbles of the interstitial gas which can still be present after the phase of saturation. At the end of the consolidation, the quality of the saturation is evaluated by the measurement of the coefficient of Skempton (B).

The degree of saturation is controlled during a triaxial compression test by the coefficient of Skempton which can be related to the degree of saturation by the following relation (Lade and Hernandez, 1977) [16]:

$$
B=\frac{1}{1+n k_{s}\left(\frac{S_{r}}{k_{w}}+\frac{1-S_{r}}{u_{a}}\right)}
$$

where $k_{s}$ and $k_{w}$ indicate the bulk modulus of the soil skeleton and the water, respectively; $n=$ the soil porosity, $u_{a}=$ water pore pressure.

The tests were carried on if the coefficient B was higher than 0.91 for the almost saturated samples, and the backpressure used is $400 \mathrm{kPa}$. For the over consolidated samples, the samples were first subjected to a medium stress of initial preconsolidation $\sigma_{c}^{\prime}$; then we remove this stress of preconsolidation and we consolidate the sample with $\sigma_{0}^{\prime}$ and the overconsolidation OCR is equal to $\sigma_{c}^{\prime} / \sigma_{0}^{\prime}$.

\section{Results of the tests conducte}

\subsection{Influence of the degree of saturation}

\subsubsection{Drained compression tests}

Fig. 7 shows the results of the drained compression tests carried out for coefficients of Skempton (B) ranging between 13 and $90 \%$. It is clear from this figure that the coefficient of Skempton (B) significantly affects the variation of the deviatoric stress (Fig. 7 (a)) and the volumetric deformation (Fig. 7(b)). The increase in the coefficient of Skempton (B) from 13 to $90 \%$ induces a reduction in the initial stiffness and resistance of the soil (maximal deviator). With regard to the volumetric deformation, we note that the increase in the coefficient of Skempton (B) delays the appearance of dilatancy; the sample with a degree of saturation $B=13 \%$ dilatancy appears after $3 \%$ of axial deformation, while for the sample with a degree of saturation $B=90 \%$ we observe an amplification of the phase of contractance and dilatancy is delayed and appears after $12 \%$ of axial deformation.

\subsubsection{Undrained compression tests}

Fig. 8 shows the results of the undrained triaxial compression tests performed in this study for various values of coefficient of Skempton (B) between 32 and 90\% with an initial confining pressure of $100 \mathrm{kPa}$. As can be seen, increase in the degree of saturation characterized by the coefficient of Skempton (B) lead to a reduction in the resistance of the deviatoric stress (Fig. 8 (a)) and an increase in the water pressure (Fig. 8 (b)). This increase in the water pressure results from the role of the degree of saturation in the increase in the phase of contractance observed during the drained tests. The increase in the pore water pressure 


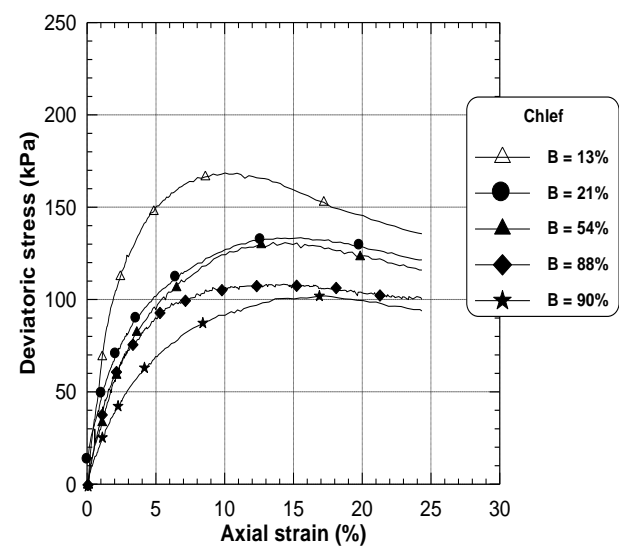

(a)

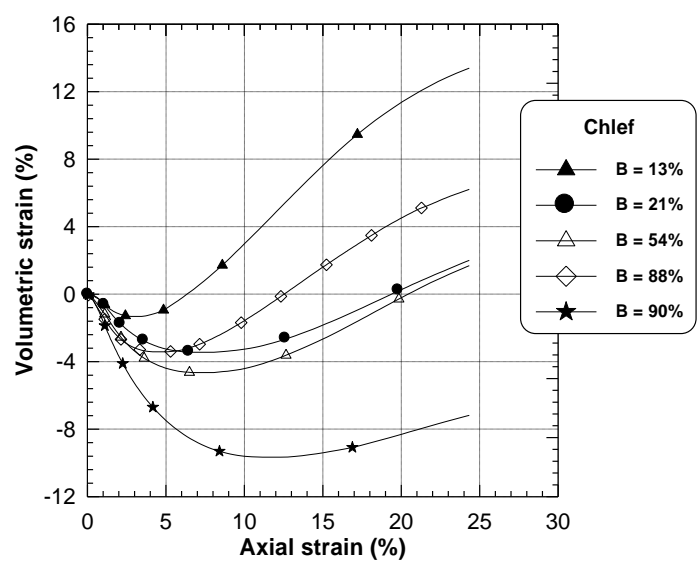

(b)

Fig. 7. Influence of the coefficient of Skempton (B) on drained response of Chlef sand

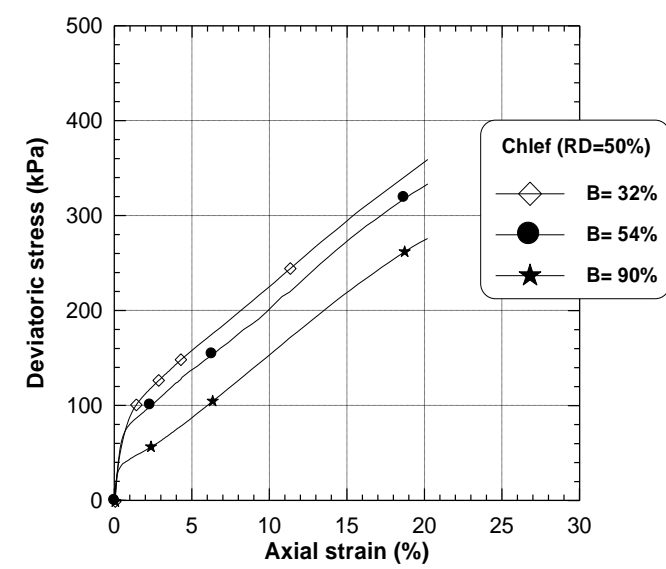

(a)

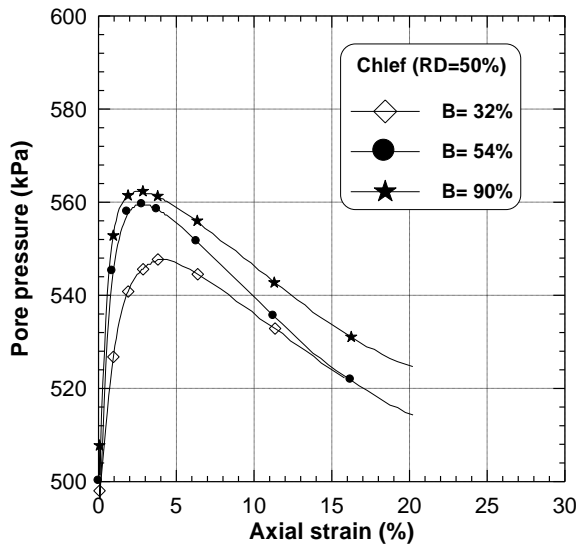

(b)

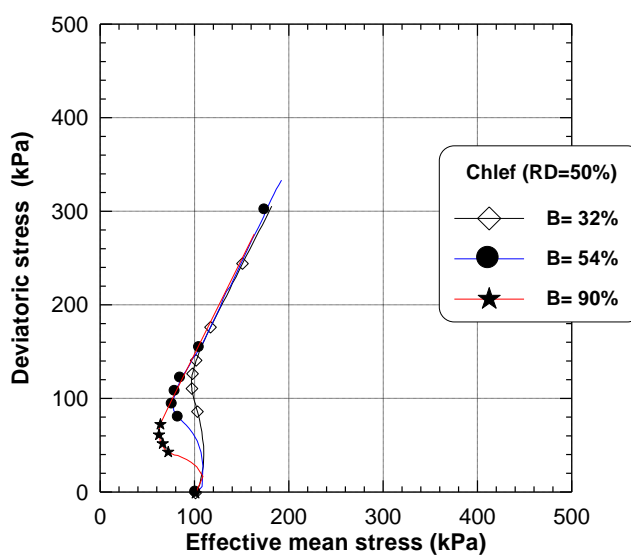

(c)

Fig. 8. Influence of the coefficient of Skempton (B) on undrained behavior of Chlef sand. (a) Deviatoric stress, (b) Pore pressure, (c) Stress path

leads to a reduction of the effective confining pressure and consequently with a reduction of resistance as Fig. 8 (a) illustrates. The stress path curve in the plan (p', q) shows well the role of the degree of saturation in the reduction of the effective mean stress and the maximal deviatoric stress (Fig. 8(c)).

\subsection{Influence of overconsolidation}

\subsubsection{Drained compression tests}

Fig. 9 shows the results of the drained compression tests carried out for the overconsolidation ratio (OCR) ranging between 1 and 8. It can be noticed that the OCR affects significantly the variations of the deviatoric stress (Fig.9(a)) and the volumetric strain (Fig. 9 (b)). The increase in the report of OCR from 1 to 8 induces an increase in the initial stiffness of sand and resistance (maximal deviatoric stress). It can also be observed for 


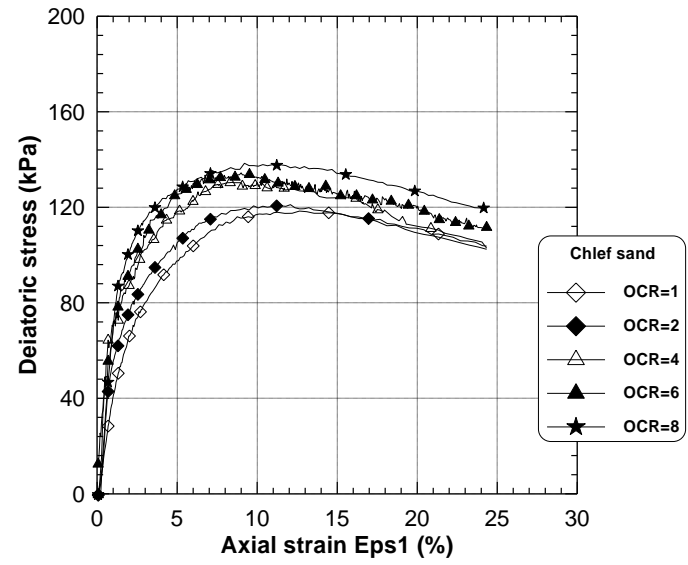

(a)

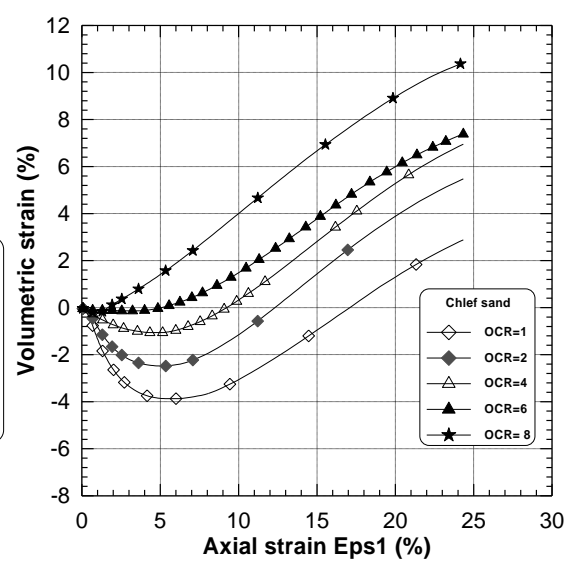

(b)

Fig. 9. Influence of overconsoldation ratio on the drained response of Chlef sand. (a) Deviatoric stress, (b) Volumetric strain

the volumetric strain that the increase in the OCR accelerates the appearance of dilatancy; the sample with an OCR equal to 8 , the dilatancy appears after $0.25 \%$ of axial strain, whereas the sample with an OCR equal to 1 we observe an amplification of the phase of contractance and dilatancy is delayed and appears after $5 \%$ of axial strain.

\subsubsection{Undrained compression tests}

Fig. 10 shows the results of the undrained compression tests carried out for various values of OCR at an initial confining pressure of $100 \mathrm{kPa}$. It can be observed that the increase in the OCR leads to an increase in the resistance of the deviatoric stress (Fig.10 (a) and consequently to a decrease in the water pressure (Fig. 10 (b)). This quick fall of the water pressure for the great values of OCR results from the role of significant dissipation of water and the reduction of the void index during the phase of initial preconsolidation observed during the drained tests. We also note that the reduction in the overconsolidation ratio delays and attenuates the appearance of the peak of the pore water pressure (corresponding to the rate of variation of the pore water pressure), it corresponds to $0.4 \%$ of axial strain for the test with an OCR equal to 8 ; whereas it occurs at $2 \%$ for the test with an OCR equal to 1 normally consolidated (Fig. 10(b)). The decrease in the interstitial pressure leads to an increase in the effective confining pressure and consequently to an increase in the resistance to the deviatoric stress as Fig. 10 (a) illustrates. The stress path in the plane (p', q) better shows the role of the overconsolidation ratio in the increase of the effective mean pressure and the maximal deviator (Fig. 10 (c)).

\section{Influence of saturation and overconsolidation on the mechanical characteristics}

\subsection{Influence of saturation}

Fig. 11 (a) presents the evolution of the secant modulus of deformation $(\mathrm{q} / \varepsilon \mathrm{a})$ according to the axial deformation $(\varepsilon \mathrm{a})$. It can be observed that this module decreases with the increase in the coefficient of Skempton (B). This reduction is very significant up to a deformation of $10 \%$, then the secant modulus tends to stabilize. Fig. 11 (b) shows the influence of the coefficient of Skempton (B) on the secant modulus of deformation measured to $\varepsilon \mathrm{a}=1 \%$. As can be seen this modulus decreases with the increase in the coefficient of Skempton (B), then it tends to stabilize for the large values of B (Fig. 11(c)); for the high deformations, the coefficient of Skempton (B) has little influence on the secant modulus.

Fig. 12 shows the influence of the coefficient of Skempton (B) on the frictional angle at the end of shearing and the characteristic angle (phase change contractance-dilatancy). It can be noticed that the two lines tracing the evolution of the frictional angle and the characteristic angle are almost parallel to each other. We note that these two angles decrease (according to a quasi-linear relation) from $24^{\circ}$ to $19^{\circ}$ and $23^{\circ}$ to $19^{\circ}$ when the coefficient of Skempton (B) increases from 13 to $90 \%$, respectively. The reduction of the frictional angle and the characteristic angle with the increase in the coefficient of Skempton (B) explain the role of saturation in the increase in the phase of contractance of the studied sand. The variation of the angle of dilatancy $(\psi)$ according to the coefficient of Skempton (B) is shown in Fig. 13. We note that this angle decreases in a quasilinear way when the coefficient of Skempton (B) increases from 13 to $90 \%$.

\subsection{Influence of overconsolidation}

Fig. 14 (a) shows the evolution of the secant modulus versus the axial strain. It can be observed that this modulus decreases with the increase in the OCR. This reduction is very significant till a deformation of $15 \%$, then the secant modulus tends to stabilize. Fig. 14 (b) shows the influence of the overconsolidation ratio on the secant modulus of deformation measured $\varepsilon_{a}=1,5$, $10,15,20$ and $24 \%$. It can be noticed that this modulus grows in a significant way when the OCR increases from 1 to 4 , then it tends to stabilize for the large values of OCR for the value of deformation $\varepsilon_{a}=1 \%$. We note that the overconsolidation ratio has a little influence on the secant modulus (E) for the large deformations. 


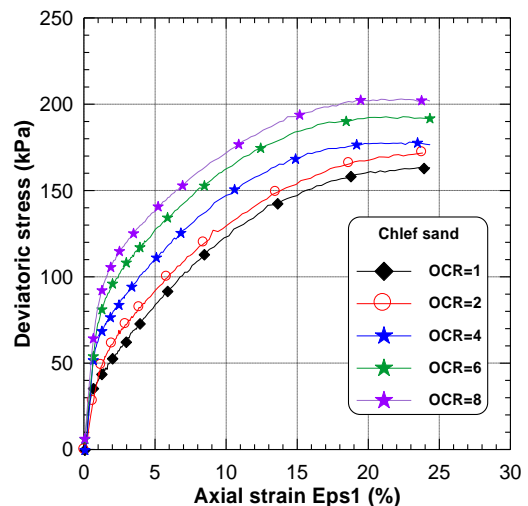

(a)

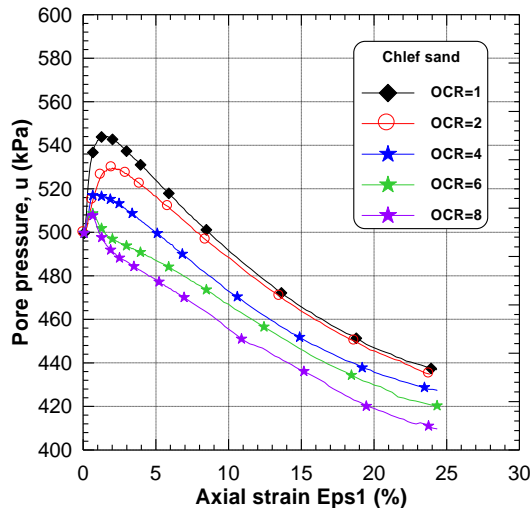

(b)

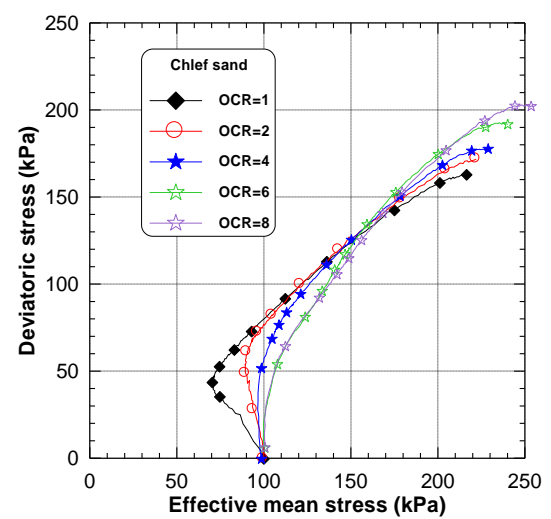

(c)

Fig. 10. Influence of overconsoldation ratio on the undrained response of Chlef sand. (a) Deviatoric stress, (b)Pore pressure, (c) Stress path

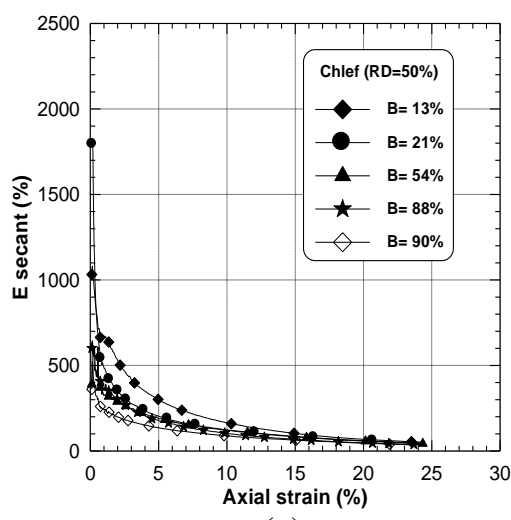

(a)

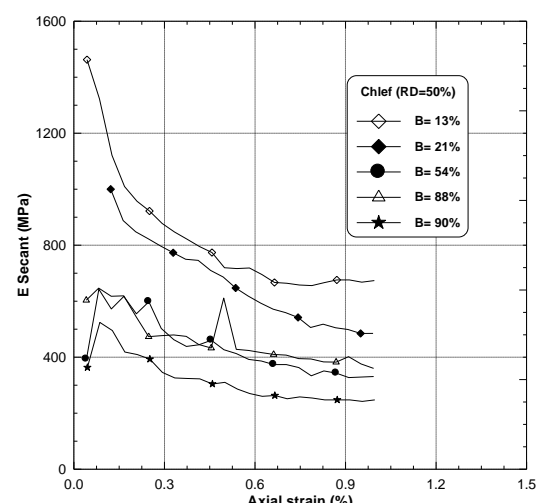

(b)

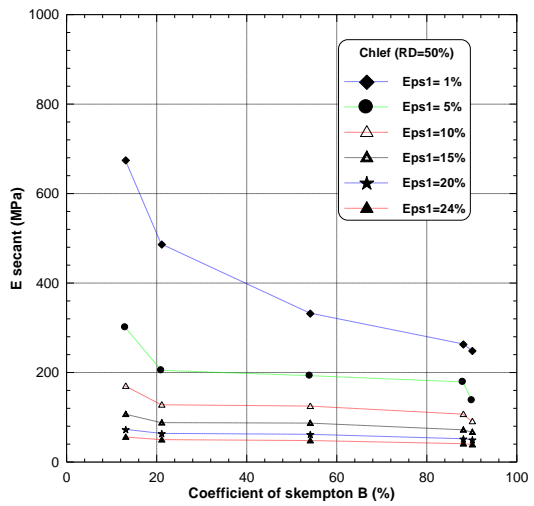

(c)

Fig. 11. Influence of the coefficient of Skempton (B) on the secant modulus of deformation: (a) Variation of the secant modulus with the axial deformation, (b) Secant Modulus with $\varepsilon a=0.01$, (c) Evolution of the secant modulus E with the coefficient of Skempton (B) 


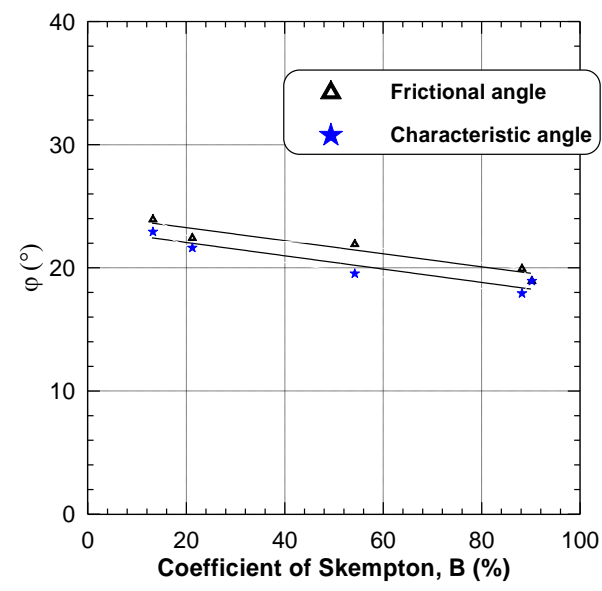

Fig. 12. Influence of the coefficient of Skempton (B) on the frictional angle and the characteristic angle

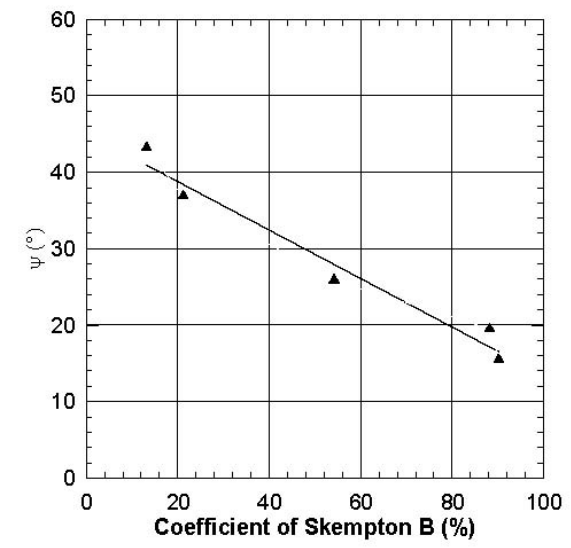

Fig. 13. Influence of the coefficient of Skempton (B) on the angle of dilatancy

Fig. 15 shows the influence of the OCR on the frictional angle at stable state and the characteristic angle at the phase change contractance-dilatancy. It can be noticed that the two lines tracing the evolution of the frictional angle at a stable state, the angle at the peak of deviatoric stress and characteristic angle move in a linear way with the OCR. It can be noted that these angles grow (according to a quasi-linear relation) from $20^{\circ}$ to $21.5^{\circ}, 22^{\circ}$ to $24^{\circ}$ and $19^{\circ}$ to $22.5^{\circ}$ when the OCR increases from 1 to 8 .

The increase in the frictional angle at a stable state, at the peak of deviatoric stress and the characteristic angle with the increase in the OCR explain the role of the overconsolidation in the reduction of the phase of contractance and the increase in the phase of contractance of the studied sand. Fig. 16 shows the variation of the dilatancy angle $(\psi)$ versus overconsolidation ratio (OCR). We note that this angle of dilatancy $(\psi)$ grows in a quasi-linear way and varies from $26^{\circ}$ to $29^{\circ}$ when the OCR increases from 1 to 8 .

\section{Residual strength}

When sands are subjected to an undrained shearing, after the peak of deviatoric stress, the resistance to the shearing falls with an almost constant value on a broad deformation. Convention- ally, this resistance to the shearing is called residual strength or the shearing force at the quasi steady state (Qss). The residual strength is defined by Ishihara (1993) as

$$
S_{u s}=\frac{q_{s}}{2} \cos \phi_{s}
$$

where $q_{s}$ and $\phi_{s}$ indicate the deviatoric stress and the mobilized angle of interparticle friction at the quasi steady state.

Fig. 17 and 18 show the evolution of the residual strength versus the coefficient of Skempton B and the OCR. It can be observed from Fig. 17 that the residual strength $\left(S_{u s}\right)$ decreases in a significant and linear way with the increase in the coefficient of Skempton (B) resulting from the role of saturation as for the amplification of the contractance of the studied soil. The evolution of the residual strength versus the OCR is illustrated in Fig. 18. It can be noticed that the residual strength grows in a quasi-linear way with the increase in the OCR; this growth is due to the reduction of the void ratio at the time of the phase of initial preconsolidation and the dissipation of the water pressure, and consequently to the increase in the dilatancy of the studied sand.

\section{Conclusion}

The results of an experimental program that investigated the effects of the saturation characterized by the coefficient of Skempton (B) and the overconsolidation ratio (OCR) on the behavior of granular sand are presented. Both drained and undrained triaxial compression tests were performed at an initial effective confining pressure of $100 \mathrm{kPa}$, on specimens prepared by the dry funnel pluviation method with an initial relative density of $R D=50 \%$, for the coefficient of Skempton (B) varying between 13 and $90 \%$ and for overconsolidation ratio (OCR) varying between 1 and 8 .

The results of the tests show that the increase in the coefficient of Skempton (B) from $13 \%$ to $90 \%$ induces a reduction of both the initial stiffness of the soil and the resistance (maximal deviatoric stress), and increases the phase of contractance.

The increase of the coefficient of Skempton (B) induces a reduction of the frictional angle and the characteristic angle of the sand (the frictional angle and the characteristic angle decrease from $24^{\circ}$ to $19^{\circ}$ and $23^{\circ}$ to $19^{\circ}$ when the coefficient of Skempton (B) increases from $13 \%$ to $90 \%$ ). This results in a significant effect on the volumetric behavior which appears by an amplification of the phase of contractance when the coefficient of Skempton (B) increases. The secant modulus of deformation decreases with the increase in the coefficient of Skempton (B), then it tends to stabilize for the great values of the coefficient of Skempton B; for the great deformations, it has a little influence on the secant modulus.

The increase in the overconsolidation ratio (OCR) leads to an increase in the initial stiffness of the sand and its resistance (maximal deviatoric stress), and consequently to a decrease of water pressure. For the volumetric strain, it can be seen that the increase in the overconsolidation ratio (OCR) accelerates the 


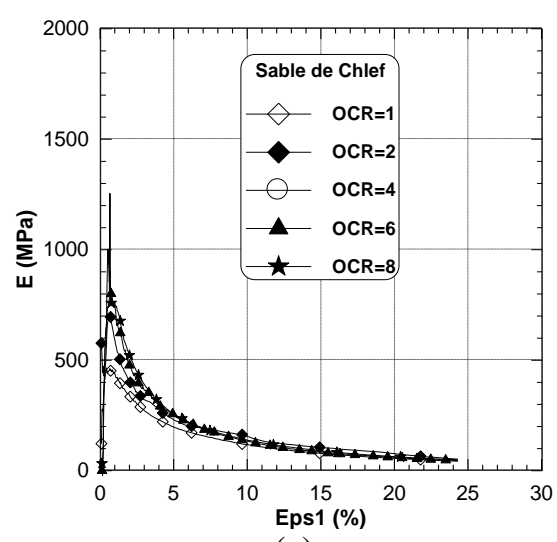

(a)

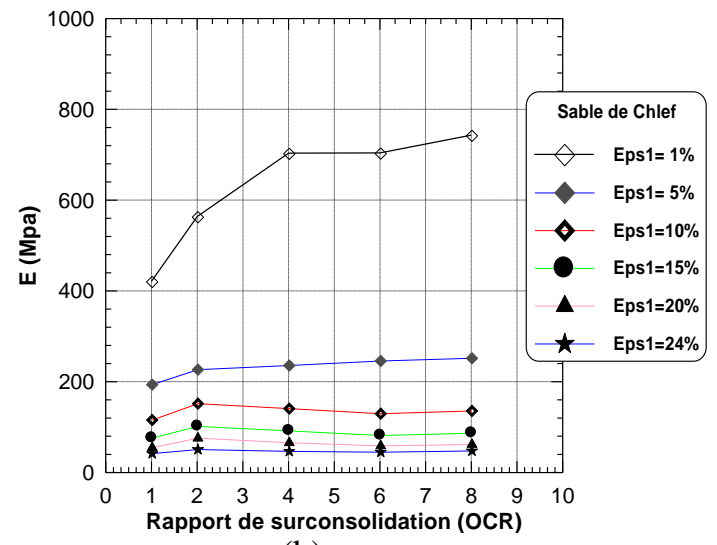

(b)

Fig. 14. Influence of overconsolidation ratio (OCR) on the secant modulus. (a) Variation of the secant modulus with the axial deformation, (b) Secant mod-

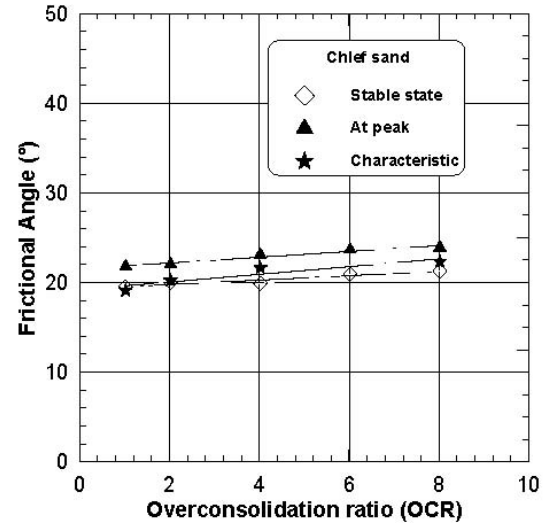

Fig. 15. Influence of overconsolidation ratio (OCR) on the frictional angle

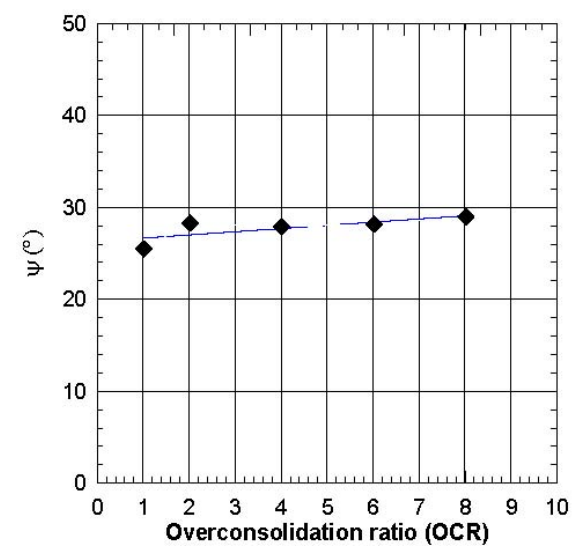

Fig. 16. Influence of overconsolidation ratio (OCR) on the dilatancy angle

appearance of dilatancy. The increase in the overconsolidation ratio (OCR) induces an increase in both the frictional angle at a steady state, and the characteristic angle (the frictional angle at a steady state, and the characteristic angle increase according to a quasi-linear relation from $20^{\circ}$ to $21.5^{\circ}$, and $19^{\circ}$ to $22.5^{\circ}$ when the overconsolidation ratio (OCR) increases from 1 to 8 ). The secant modulus grows in a significant way when the overconsolidation ratio increases from 1 to 4 , then it tends to stabilize for the great values of OCR; for the great values of deformation, the secant modulus varies a little with the increase in the overconsolidation ratio. ulus at $\varepsilon_{a}=0.01$

The residual effort $\left(S_{u s}\right)$ decreases in a significant and linear manner with the increase in the coefficient of Skempton (B) resulting from the role of saturation as for the amplification of the contractance of the studied sand and grows in a quasi-linear way with the increase in the overconsolidation ratio (OCR); this growth is due to the reduction in the void ratio at the time of the phase of initial preconsolidation.

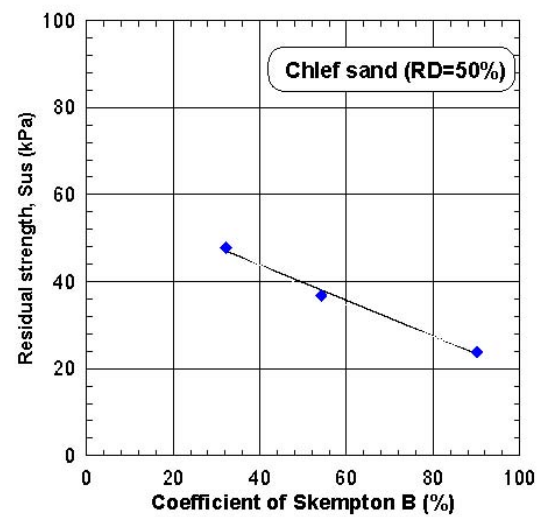

Fig. 17. Influence of Skempton's pore pressure coefficient (B) on the residual strength $\left(S_{u s}\right)$

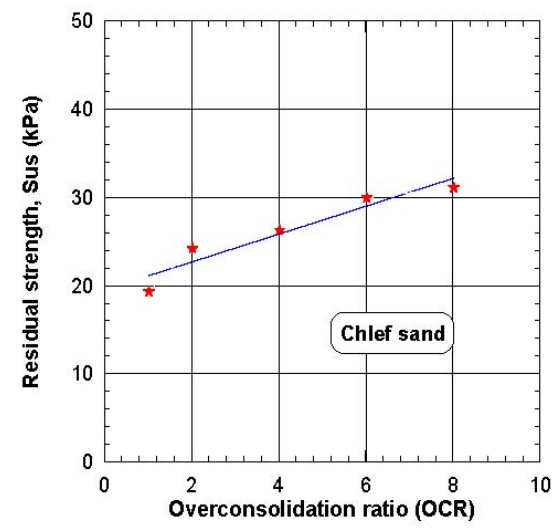

Fig. 18. Influence of overconsolidation ratio OCR on the residual strength (Sus) 


\section{References}

1 Al Mahmoud M, Etude en laboratoire du comportement des sables sous faibles contraintes, Université des sciences et techniques, USTL, Lille, France, 1997. PhD thesis.

2 Ambraseys $\mathbf{N}$ N, The El-Asnam earthquake of 10 october 1980: conclusions drawn from a field study, Quarterly Journal of Engineering Geology (1981), no. $14,143-148$.

3 Atigh E, Byrne P M, Liquefaction flow of submarine slopes under partially undrained conditions: an effective stress approach, Canadian geotechnical journal 41 (2004), no. 1, 154-165.

4 Biarez J, Ziani F, Introduction aux lois de comportement des sables très peu denses, Revue francaise de géotechnique (1991), no. 54, 65-73.

5 Bishop A W, Wesley L D, A hydraulic triaxial apparatus for controlled stress path testing, Geotechnique 25 (1975), no. 4, 657-670.

6 Bouferra R, Etude en laboratoire de la liquéfaction des sols, Université des sciences et techniques, USTL, Lille, France, 2000. PhD thesis.

7 Bouferra R, Benseddiq N, Shahrour I, Saturation and preloading effects on the cyclic behavior of sand, International journal of geomechanics, ASCE 7 (2007), no. 5, 396-401.

8 Colliat $\mathbf{J} \mathbf{L}$, Comportement des matériaux granulaires sous forte contraintes, influence de la nature minéralogique du matériau étudié, Institut de mécanique de Grenoble, IMG, Grenoble, France, 1986. PhD thesis.

9 Flavigny E, Desrues J, Palayer B, Le sable d'Hostun Rf, Revue française de géotechnique (1990), no. 53, 67-70.

10 Hoque E, Tatsuoka F, Anisotropy in the elastic deformation of granular materials, Soils and Foudations 38 (1998), no. 1, 163-179.

11 Ishihara K, Sodekawa M, Tanaka Y, Effects of surconsolidation on liquefaction characteristics of sands containing fines, Dynamic Geotechnical testing (1978), no. 654, 246-264.

12 Ishihara K, Takatsu H, Effects of oversurconsolidation and KO conditions the liquefaction characteristics of sands, Soils and Foundations 19 (1979), no. 4, 59-68.

13 Ishihara K, Tsuchiya H, Huang Y, Kamada K, Recent studies on liquefaction resistance of sand effect of saturation, Recent Advances in Geotech. Earthquake Engineering and Soil Dynamics (San Diego, 2001).

14 Ishihara K, Tsukamoto Y, Kamada K, Undrained behavior of nearsaturated sand in cyclic and monotonic loading, Cyclic Behavior of Soils and Liquefaction Phenomena (Bochum, Germany), 2004, pp. 27-39.

15 Lade P V, Duncan J M, Cubical triaxial tests on cohesionless soil, Journal of the Soil Mechanics and Foundations Division 99 (1993), no. 10, 793-812.

16 Lade P V, Hernandez S B, Membrane penetration effects in undrained tests, Journal of the Geotechnical Engineering Divis 103 (1977), no. 2, 109125.

17 Lancelot L, Shahrour I, Al Mahmoud M, Comportement du sable d'Hostun sous faibles contraintes, Revue Française de Geotechnique (1996), no. 74, 63-74.

18 Lee K L, End restraint effct on undrained static triaxial strength of sand, Journal of the Geotechnical Engineering Division 104 (1978), no. 6, 687704.

19 Martin G R, Seed H D, Finn W D L, Effects of system compliance on liquefaction tests, Journal of the Geotechnical Engineering Division 104 (1978), no. 4, 463-479.

20 Mathiroban S, Grozic J, A model to predict the undrained response of loose gassy sand, Canadian Geotechnical Conference (Quebec City, Canada), 2004.

21 McKenzie D, Active tectonics of the Mediterranean region, Geophysical Journal of the Royal Astronomical Society 30 (1972), no. 2, 109-185.

22 Mulilis J P, Townsend F C, Horz R C, Triaxial testing techniques and sand liquefaction, Dynamic Geotechnical Testing (1978), no. 654, 265-279.

23 Nakazawa H, Ishihara K, Tsukamoto Y, Kamata T, Case studies on eval- uation of liquefaction resistance of imperfectly saturated soil deposits, Cyclic Behavior of Soils and Liquefaction Phenomena (Germany), 2004.

24 Ouyed M, Le tremblement de terre d'El-Asnam du 10 octobre 1980: étude des répliques, Université de Grenoble, IMG, Grenoble, France, 1981. PhD thesis.

25 Papastamatiou D, El-Asnam, Algeria earthquake of October 10, 1980: field evidence of ground motion in the epicentral region, Geognosis (1980).

26 Pietruszczak S, Pande G, Oulapour M, A hypothesis for mitigation of risk of liquefaction, Geotechnique $\mathbf{5 3}$ (2003), no. 9, 833-838.

27 Robinet J C, Mohkam M, Doanh D, Torrenti J M, Amelioration des apparaiels triaxiaux pour les sols et les bétons, Méthodes et appareils de mesures rhéologiques (Paris), 1983.

28 Rothé J P, Le tremblement de terre d'Orléanville et la séismicité de l'Algérie, La nature (1955), no. 3237, 1-9.

29 Seed H B, Idriss I M, Lee K L, Dynamics analysis of the slide in the lower San Fermondo dam during the earthquake of February 1971, Journal of the Geotechnical Engineering division 101 (1975), no. 9, 889-911.

30 Seed H B, Peacock W H, Test procedures for measuring soil liquefaction characteristics, Journal of the Soils Mechanics and Foundation Division 97 (1971), no. 8, 1099-1119.

31 Tatsuoka F, Molenkamp F, Torii T, Hino T, Behavior of lubrication layers of platens in element tests, Soils and Foundations 24 (1984), no. 1, 113-128.

32 Thevenin J, Les effets du seisme de septembre 1954 sur les ouvrages hydrauliques de la region d'Orléanville, Terre et Eaux (1955), no. 24, 58-66.

33 Yang $\mathbf{J}$, Liquefaction resistance of sand in relation to $P$-wave velocity, Geotechnique 52 (2002), no. 4, 295-298.

34 Yang J, Sato T, Analytical study of saturation effects on seismic vertical amplification of a soil layer, Geotechnique 51 (2001), no. 2, 161-165.

35 Yang J, Savidis S, Roemer M, Evaluating liquefaction strength of partially saturated sand, Journal of Geotechnical and Geoenvironmental.Engineering 130 (2004), no. 9, 975-979.

36 Yoshimi Y, Tanaka K, Tokimatsu K, Liquefaction resistance of partially saturated sand, Soils and foundations 29 (1989), no. 3, 157-162. 